\title{
Review of Fabrication and Characterization of Nd-Fe-B Thick Films for Magnetic Micromachines
}

\author{
M. Nakano ${ }^{1}$, S. Sato ${ }^{1}$, F. Yamashita ${ }^{2}$, T. Honda ${ }^{3}$, J. Yamasaki ${ }^{3}$, K. Ishiyama ${ }^{4}$, M. Itakura ${ }^{5}$, J. Fidler ${ }^{6}$, \\ T. Yanai ${ }^{1}$, and H. Fukunaga ${ }^{1}$
}

\author{
${ }^{1}$ Department of Electrical Engineering and Electronics, Nagasaki University, Nagasaki 852-8521, Japan \\ ${ }^{2}$ Motor Technology Center, Matsushita Electric Industrial Co., Ltd., Osaka 574-0044, Japan \\ ${ }^{3}$ Department of Applied Science for Integrated System Engineering, Kyushu Institute of Technology, Kitakyushu 804-8550, Japan \\ ${ }^{4}$ Research Institute of Electrical Comunication, Tohoku University, Sendai 980-8577, Japan \\ ${ }^{5}$ Department of Applied Science for Electronics and Materials, Kyushu University, Fukuoka 816-8580, Japan \\ ${ }^{6}$ Vienna University of Technology, A-1040 Vienna, Austria
}

\begin{abstract}
Isotropic Nd-Fe-B thick film magnets were prepared by a high-speed pulsed laser deposition method followed by a post annealing. The deposition rate of $90 \mu \mathrm{m} / \mathrm{h}$ could be successfully achieved, and a pulse annealing was adopted as the post annealing process in order to enhance coercivity. Use of a substrate heating system under the high deposition rate enabled us to obtain anisotropic thick films with $(B H)_{\max }$ of approximately $120 \mathrm{~kJ} / \mathrm{m}^{3}$, which show the potential for an improvement in the properties of the micromachines. Novel micromachines comprising the isotropic films were introduced.
\end{abstract}

Index Terms-Laser ablation, micromachines, micromotors, thick film devices.

\section{INTRODUCTION}

$\mathbf{N}$ UMEROUS studies [1], [2] on microactuators and micromachines comprising small permanent magnets indicate that reduction in thickness for bulk magnets without deterioration of magnetic properties [3]-[5] and preparation of thick film magnets [6]-[9] thicker than $10 \mu \mathrm{m}$ are key points to developing magnetic microactuators and systems (MAGMAS). For example, Nienhaus et al. have prepared disk-rotors made from $\mathrm{Nd}-\mathrm{Fe}-\mathrm{B}$ powders for planer micromotors [2]. Nakamura [4] et al. prepared a 100- $\mu$ m-thick sintered bulk magnet with $(B H)_{\max }$ of $245 \mathrm{~kJ} / \mathrm{m}^{3}$ by using refinement of grain size and surface treatment after a mechanical etching process. Since Cadieu [6] has reported a $40-\mu$ m-thick Sm-Co film magnet in 1989, many researchers have reported sputtering-made anisotropic thick film magnets prepared under the high deposition rate of 20-40 $\mu \mathrm{m}$. Recently, Uehara [9] also reported high $(B H)_{\max }$ value of $279 \mathrm{~kJ} / \mathrm{m}^{3}$. In addition, other fabrication methods for thick film magnets such as the aerosol deposition method [10], plasma spraying [11], and tape casting [12] have been reported.

In our study, the pulsed laser deposition (PLD) method was used for preparing thick film magnets applied to various applications. Some researchers have reported PLD-prepared $\mathrm{Nd}-\mathrm{Fe}-\mathrm{B}$ [13], [14], Sm-Co [15], and Sm-Fe-N films [16], and the thickness of almost all the samples was less than $1 \mu \mathrm{m}$ because the aims in fabricating the films were based on application for recording media and physical interest such as the epitaxial method. We prepared $\mathrm{Nd}-\mathrm{Fe}-\mathrm{B}$ film magnets thicker

Digital Object Identifier 10.1109/TMAG.2007.893778

Color versions of one or more of the figures in this paper are available online at http://ieeexplore.iee.org.

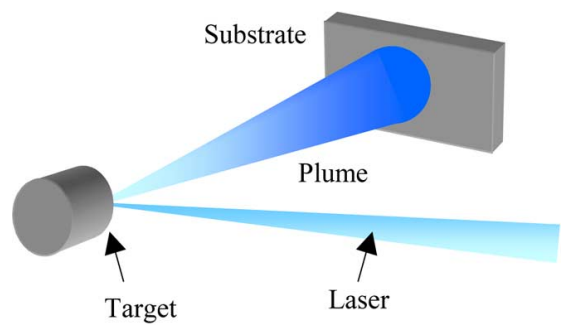

Fig. 1. Diagram of PLD method. The distance between a target and a substrate was fixed at $10 \mathrm{~mm}$. The laser power was controlled from 3 to $10 \mathrm{~W}$ at an irradiation exit of a laser system.

than $20 \mu \mathrm{m}$ under the deposition rate of $20-40 \mu \mathrm{m} / \mathrm{h}$ by the PLD method [17]. In addition, the thick films were applied to a dc brush-less motor [18], a micromachine swimming in liquid [19], and an electromagnetic friction-drive motor.

This contribution reports the magnetic properties and structure for the PLD-fabricated isotropic Nd-Fe-B films under the high deposition rate up to $90 \mu \mathrm{m} / \mathrm{h}$. Improvement in magnetic properties by preparing anisotropic films using a substrate heating system [18] was introduced. We also reviewed three applications comprising the isotropic films [19], [20].

\section{PREPARATION OF Thick Film Magnets}

We used a high-speed PLD method to fabricate $\mathrm{Nd}-\mathrm{Fe}-\mathrm{B}$ thick film magnets. In order to compensate loss of metallic $\mathrm{Nd}$ due to oxidation, the nominal composition of targets was set to $\mathrm{Nd}_{2.4} \mathrm{Fe}_{14} \mathrm{~B}$, which include a larger amount of $\mathrm{Nd}$ than the stoichiometric composition. These targets were ablated with a $\mathrm{Nd}-$ YAG pulse laser $(\lambda=355 \mathrm{~nm})$ at the repetition rate of $30 \mathrm{~Hz}$, and the distance between a target and various substrates such as Ta and Fe was fixed at $10 \mathrm{~mm}$, as shown in Fig. 1. The deposition rate was varied from 20 to $90 \mu \mathrm{m} / \mathrm{h}$ by controlling the laser power from 3 to $10 \mathrm{~W}$ at the irradiation exit of a Nd-YAG laser system. Before the ablation, the chamber was evacuated down to about $10^{-4} \mathrm{~Pa}$ with a molecular turbo pump. 


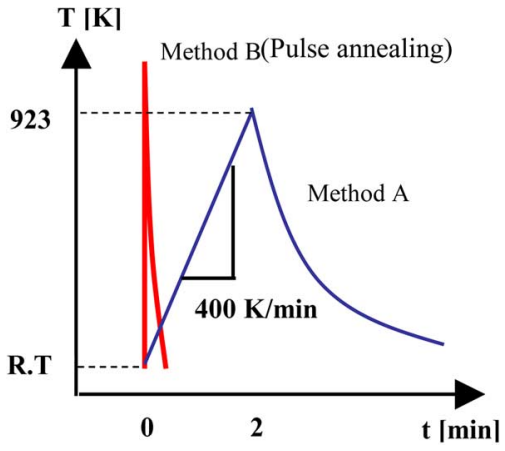

Fig. 2. Diagram of postannealing processes after deposition. In Method A, the samples were heated up to the designated temperature $(923 \mathrm{~K})$ under the heating rates of $400 \mathrm{~K} / \mathrm{min}$ with an infrared furnace, and then they were cooled down to room temperature. In Method $\mathrm{B}$, a pulse annealing with a high heating rate beyond $850 \mathrm{~K} / \mathrm{min}$ was done.

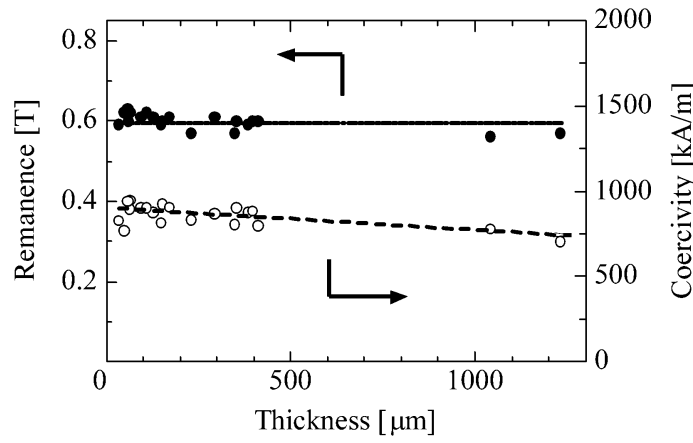

Fig. 3. Magnetic properties of remanence and coercivity in PLD-made $\mathrm{Nd}-\mathrm{Fe}-\mathrm{B}$ films as a function of film thickness. Although the coercivity slightly decreased as the thickness increased, the remanence was almost constant in the thickness range of $20-1200 \mu \mathrm{m}$.

The structure of all the as-deposited films prepared without using a substrate heating system was amorphous. In order to form the $\mathrm{Nd}_{2} \mathrm{Fe}_{14} \mathrm{~B}$ crystallized structure, the as-deposited films were postannealed under the vacuum of $10^{-3} \mathrm{~Pa}$ by using two methods, Methods A and B. In Method A, the samples were heated up to the designated temperature of $923 \mathrm{~K}$ under the heating rate of $400 \mathrm{~K} / \mathrm{min}$ with an infrared furnace, and then they were cooled down to room temperature. In Method B, a pulse annealing with a high heating rate beyond $850 \mathrm{~K} / \mathrm{min}^{21}$ was carried out as displayed in Fig. 2.

In-plane and perpendicular $M-H$ loops were measured with a vibrating sample magnetometer under an applied field up to $2.5 \mathrm{~T}$. Before the measurement, a pulsed field exceeding $8 \mathrm{~T}$ was applied to all the samples in order to magnetize. The analysis of crystal structure was carried out with an X-ray diffractometer. Thickness was measured with a digital micrometer. Nd-Fe-B films with the thickness range up to $1200 \mu \mathrm{m}$ could be successfully obtained without deterioration of mechanical properties although the coercivity slightly decreased as the thickness increased (see Fig. 3).

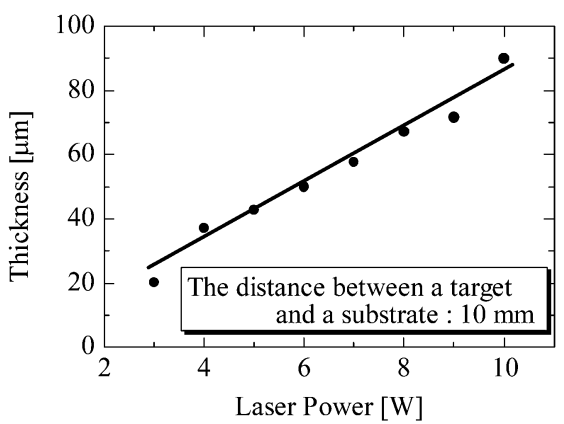

Fig. 4. Dependence of thickness on laser power in PLD-made Nd-Fe-B thick film magnets. Deposition time was fixed at $1 \mathrm{~h}$. Increase in the power enabled us to increase the deposition rate.

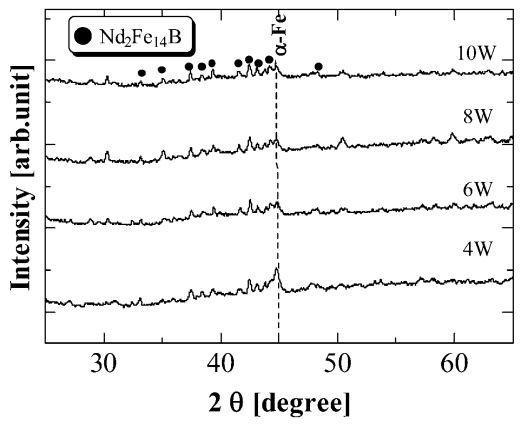

Fig. 5. X-ray diffraction patterns of annealed Nd-Fe-B thick film magnets The films were prepared under various laser powers. The peaks corresponding to $\mathrm{Nd}_{2} \mathrm{Fe}_{14} \mathrm{~B}$ phases were observed in all the samples.

\section{MAGNeTIC PROPERTIES OF ISOTROPIC THICK FILM MAGNETS}

\section{A. Isotropic PLD-Made Nd-Fe-B Films Prepared Under the High Deposition Rate up to $90 \mu \mathrm{m} / \mathrm{h}$}

Fig. 4 shows the thickness of PLD-made Nd-Fe-B film magnets as a function of the laser power. As the power increased, the obtained thickness increased, and resultantly, the deposition rate was proportional to the laser power, approximately $9 \mu \mathrm{m} / \mathrm{h} \cdot \mathrm{W}$. The wide deposition rate range between 20 and $90 \mu \mathrm{m} / \mathrm{h}$ could be achieved in our PLD system, and the maximum value of $90 \mu \mathrm{m} / \mathrm{h}$ was approximately two times as large as that reported by Kapitanov et al. [8].

According to observations in X-ray diffraction patterns for all the as-deposited films, the structure of the films was amorphous. Method $\mathrm{A}$ as a postannealing was executed to form $\mathrm{Nd}_{2} \mathrm{Fe}_{14} \mathrm{~B}$ phase, and then magnetic properties for the annealed samples were measured. As shown in Fig. 5, Nd-Fe-B phase was observed in the samples under various laser powers. However, precipitation of $\alpha$-Fe phase, which was attributed to the surface oxidation, was also observed. Remanence, coercivity, and $(B H)_{\max }$ showed the constant values of $1050 \mathrm{kA} / \mathrm{m}, 0.6 \mathrm{~T}$, and and $60 \mathrm{~kJ} / \mathrm{m}^{3}$, respectively, which were comparable to those previously reported [19] (see Figs. 6 and 7).

Although the surface roughness increased with increasing laser power and deposition rate, the peeling phenomenon was not observed in all the as-deposited films. We also confirmed that the postannealed films did not peel from its substrate. It is generally said that a peeling phenomenon occurs as the 


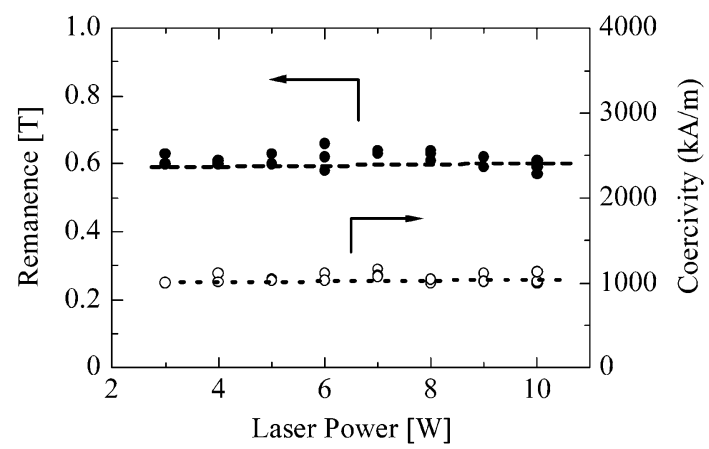

Fig. 6. Magnetic properties as a function of laser power. In the wide range of laser power between 3 and $10 \mathrm{~W}$, the remanence and coercivity showed the constant values of approximately $0.6 \mathrm{~T}$ and $1000 \mathrm{kA} / \mathrm{m}$, respectively.

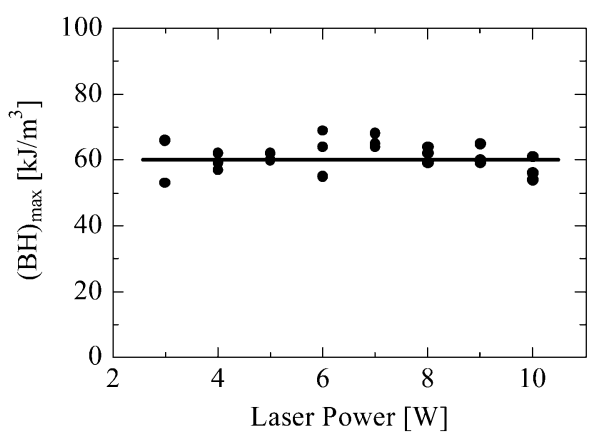

Fig. 7. $(B H)_{\max }$ as a function of laser power. In the wide range of laser power between 3 and $10 \mathrm{~W}$, the $(B H)_{\max }$ showed the constant value of approximately $60 \mathrm{~kJ} / \mathrm{m}^{3}$.

thickness of films increases because of the increase in an inner stress; however, the above-mentioned PLD-made samples did not show the peeling phenomenon. From these results, the increase in the laser power is effective in the increase in deposition rate without deterioration of magnetic and mechanical properties.

\section{B. Microstructure of Isotropic PLD-Made $\mathrm{Nd}-\mathrm{Fe}-\mathrm{B}$ Films and Adoption in a Pulse Annealing}

Investigation on microstructure of PLD-prepared Nd-Fe-B films is effective for the improvement in magnetic properties. Fig. 8 shows a transmission electron microscopy (TEM) image of a PLD-prepared isotropic film with the coercivity and remanence of $1080 \mathrm{kA} / \mathrm{m}$ and $0.59 \mathrm{~T}$, respectively. The sample shown in Fig. 8(b) was prepared by etching from the surface by an FIB. TEM observations for the inside [Fig. 8(a)] of the film and boundary on a Ta substrate [Fig. 8(c)] were executed.

The microstructure indicated that the film was mainly composed of $\mathrm{Nd}_{2} \mathrm{Fe}_{14} \mathrm{~B}$ grains whose size varied widely from 5 to $440 \mathrm{~nm}$, and the average grain size was estimated as $150 \mathrm{~nm}$. In addition, the grain growth seemed to occur directly on the substrate, because the boundary phase between the sample and the substrate did not affect the grain growth behavior in PLD-prepared thick films.

High-speed crystallization has been reported as one of hopeful methods for reducing the grain size and its distribution, and resultantly it enables us to improve the coercivity values of sputtered $\mathrm{Nd}-\mathrm{Fe}-\mathrm{B}$ films and rapid-quenched $\mathrm{Pr}-\mathrm{Fe}-\mathrm{B}$ ribbons
[21], [22]. We, therefore, adopted a pulse annealing method with a high heating rate beyond $850 \mathrm{~K} / \mathrm{min}$ (see Fig. 2). As shown in Fig. 9, coercivity strongly depended on the pulse annealing period. Resultantly, crystallization by pulse annealing for $1.8 \mathrm{~s}$ led to enhanced coercivity of the films by $300 \mathrm{kA} / \mathrm{m}$ compared with previously reported ones [17], [19]. The microstructure of pulse-annealed sample is under investigation.

\section{ANisotropic Nd-Fe-B Film Magnets Prepared BY THE HIGH-SPEED PLD METHOD WITH A SUBSTRATE HEATING SYSTEM}

We further attempted to develop the above-mentioned PLD-made Nd-Fe-B thick films, and preparation of anisotropic thick film magnets was carried out by adoption of a substrate heating system between a target and a substrate. Use of the system enabled us to obtain anisotropic $\mathrm{Nd}-\mathrm{Fe}-\mathrm{B}$ thick film magnets under a high deposition rate.

We adopted a continuous deposition method, which means that a film is continuously deposited during heating substrate. Although the obtained remanence and $(B H)_{\max }$ values of the anisotropic films were higher than those of decreased by $40 \%$ compared to that of the isotropic ones [17], [19]. The deterioration of coercivity can be attributed to a heterogeneous grain growth due to heating during the long deposition time.

In order to overcome this difficulty, we adopted a new method, in which the deposition process was intercepted repeatedly during the substrate heating. We designated this method as the interceptive deposition method (IDM). The new preparation method, IDM, was applied to the preparation of $\mathrm{Nd}-\mathrm{Fe}-\mathrm{B}$ film magnets, and it was clarified that IDM is effective in fabricating anisotropic $\mathrm{Nd}-\mathrm{Fe}-\mathrm{B}$ thick film magnets under the deposition rate of $20-50 \mu \mathrm{m} / \mathrm{h}$. Although the mechanism for the improvement in magnetic properties is under investigation, a magnetic micromotor comprising the IDM-made films is a hopeful candidate as a developed micromachine.

\section{Micromachines COMPRISING ISOTROPIC PLD-MADE $\mathrm{Nd}-\mathrm{Fe}-\mathrm{B}$ FILMS}

Fig. 10 shows the structure of a small dc brush-less motor comprising a $200-\mu \mathrm{m}$-thick isotropic PLD-prepared Nd-Fe-B film magnet, which has $971 \mathrm{kA} / \mathrm{m}$ in coercivity and $0.57 \mathrm{~T}$ in remanence, respectively. Here, the film was deposited on a Fe substrate and the thickness and diameter of the motor were 0.8 and $5 \mathrm{~mm}$, respectively. We confirmed that it rotates at $15160 \mathrm{rpm}$ under no-load test, and has torque constant of $0.0236 \mathrm{mNm} / \mathrm{A}$ at the gap of $0.1 \mathrm{~mm}$ between a rotor and a stator. The motor is applicable to a small hard disk and a vibration motor inside a mobile phone.

We have further reported a spiral type micromachine with $0.14 \mathrm{~mm}$ in outer diameter and $1.0 \mathrm{~mm}$ in length prepared by a tungsten wire deposited on $\mathrm{Nd}-\mathrm{Fe}-\mathrm{B}$ film magnet. As the film magnet was magnetized in the circumferential direction, the machine rotated in synch with the rotating external magnetic field and the spiral structure generated propellant force. In our experiment, three types of liquids with kinematic viscosity of 1,10 , and $100 \mathrm{~mm}^{2} / \mathrm{s}$, respectively, were used, and the external magnetic field of $8 \mathrm{kA} / \mathrm{m}$ was applied under the frequency range between 2 and $10 \mathrm{~Hz}$. It was found that the wireless micromachine 


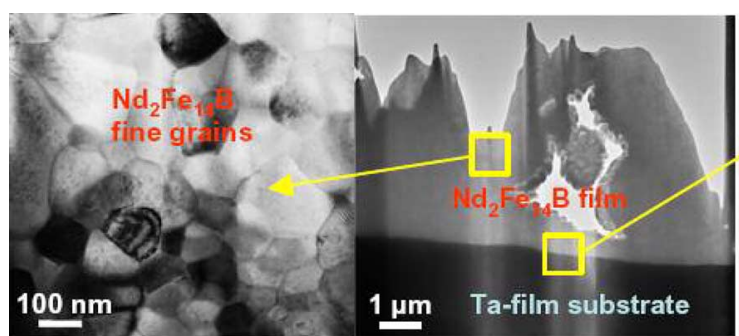

(a)

(b)

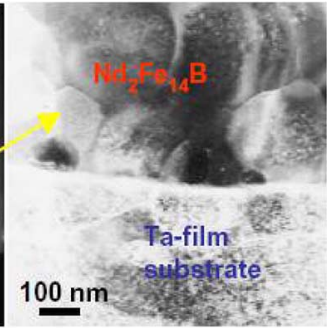

(c)

Fig. 8. Photos of TEM observations and cross sectional view for an isotropic Nd-Fe-B film magnet. (a) inside a sample, (b) TEM image in low magnification, (c) boundary on a Ta substrate.

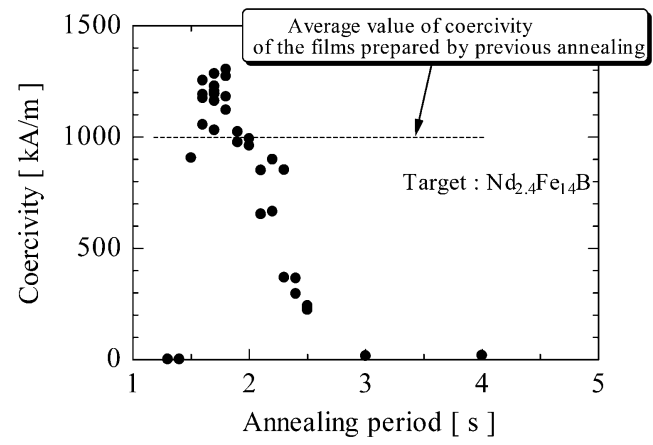

Fig. 9. After obtaining deposited Nd-Fe-B films, the samples were postannealed by a pulse annealing method. Coercivity as a function of the annealing time. Samples prepared by the pulse annealing for $1.8 \mathrm{~s}$ led to enhance coercivity of the films by $300 \mathrm{kA} / \mathrm{m}$ compared with previously reported ones.

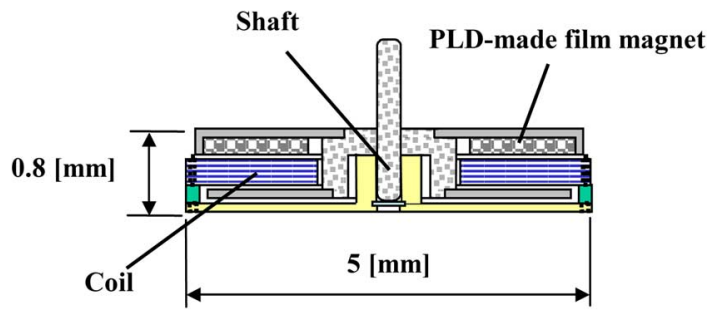

(a)

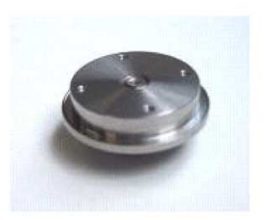

(b)

Fig. 10. Structure of a dc brush-less motor comprising a 200- $\mu$ m-thick PLDmade $\mathrm{Nd}-\mathrm{Fe}-\mathrm{B}$ film magnet. It rotates at $15160 \mathrm{rpm}$ under no-load test, and has torque constant of $0.0236 \mathrm{mNm} / \mathrm{A}$. (a) Schematic diagram of a milli-size motor. (b) Photograph of a milli-size motor

swam at the speed of $0.2-1.6 \mathrm{~mm} / \mathrm{s}$ under the various conditions. The actuator is a hopeful candidate for a drug delivery machine in human blood vessel.

Recently, a new type micromotor comprising a PLD-made $384 \mu$ m-thick Nd-Fe-B film magnet has been reported. The electromagnetic friction-drive micromotor had a large torque and a low rotational speed. The stator is a coil with a ferrite core in the center and a ferrite disc on the bottom. Alternating voltage was applied to the coil. Between the film magnet and the ferrite core, pulling and reacting forces worked alternatively, and resultantly the magnet vibrated. The rotor is magnetically mounted onto the stator without mechanical attachments. The motor rotated at approximately $300 \mathrm{rpm}$ with starting torque of approximately $2 \mu \mathrm{Nm}$. It was confirmed that the new class of micromotor using a thick film magnet is one of hopeful candidates as a new micromachine.

\section{CONCLUSION}

Isotropic $\mathrm{Nd}-\mathrm{Fe}-\mathrm{B}$ thick film magnets prepared by the highspeed PLD method could be applied to a small dc brush-less motor, a machine swimming in liquid, and an electromagnetic friction-drive micromotor. Anisotrope PLD-prepared Nd-Fe-B thick film magnets are promising materials to advance various small magnetic micromachines.

\section{ACKNOWLEDGMENT}

This work was supported in part by the Ministry of Education, Science, Sports and Culture of Japan under a Grand-in-Aid (16686022, 10136533) and in part by the Energy Use Rationalization Technology and Strategy Developments Program in 2005 from the New Energy and Industrial Technology Development Organization (NEDO, Project P03033) of Japan.

\section{REFERENCES}

[1] T. S. Chin, "Permanent magnet films for applications in microelectromechanical systems," J. Magn. Magn. Mater., vol. 209, pp. 75-79, 2000 .

[2] O. Cugat, "Rare earth permanent magnet applications in MAGMAS," in Proc. 16th Int. Workshop Rare Earth Magnets and Their Applications, Aug. 2002, pp. 478-489.

[3] H. Nakamura, K. Hirota, M. Shimao, T. Minowa, and H. Masakatsu, "Magnetic properties of extremely small Nd-Fe-B sintered magnets," IEEE Trans. Magn., vol. 41, no. 10, pp. 3844-3846, Oct. 2005.

[4] H. Nakamura, "Small Nd-Fe-B sintered magnets," IEEJ J., vol. 124-11, pp. 699-702, Nov. 2004, (in Japanese).

[5] H. Kanekiyo and S. Hirosawa, "Preparation of thin-plate $\mathrm{Fe}_{3} \mathrm{~B} / \mathrm{Nd}_{2} \mathrm{Fe}_{14} \mathrm{~B}$ nanocomposite permanent manets," J. Mag. Soc. Jpn., vol. 22, pp. 385-388, Apr. 1998.

[6] F. J. Cadieu, H. Hegde, and K. Chen, "The synthesis of $\mathrm{Sm}_{2}(\mathrm{Co}, \mathrm{Fe}$, $\mathrm{Zr})_{17}$ high energy product, 16 to 30 MGOe thick sputtered films," IEEE Trans. Magn., vol. 25, no. 5, pp. 3788-3790, Sep. 1989.

[7] S. Yamashita, J. Yamasaki, M. Ikeda, and N. Iwabucji, "Anisotropic Nd-Fe-B thin-film magnets for milli-size motor," J. Appl. Phys., vol. 70, no. 5, pp. 6627-6629, Nov. 1991.

[8] B. A. Kapitanov, N. V. Kornilov, Ya. L. Linetsky, and V. Yu. Tsvetkov, "Sputtered permanent Nd-Fe-B magnets," J. Magn. Magn. Mater., vol. 127, pp. 289-297, 1993.

[9] M. Uehara, "Microsyructure and magnetic properties of $\mathrm{Nd}-\mathrm{Fe}-\mathrm{B} / \mathrm{Ta}$ Perpendicular anisotropy multilayered films," J. Magn. Soc. Japan, vol. 28, pp. 1043-1048, 2004, (in Japanese). 
[10] S. Sugimoto, T. Maeda, R. Kobayashi, J. Akedo, M. Ledebev, and K. Inomata, "Magnetic properties of sm-Fe-N thick film magnets prepared by the aerosol deposition method," IEEE Trans. Magn., vol. 39, no. 5, pp. 2986-2989, Sep. 2003.

[11] G. Rieger, J. Wecker, W. Rodewald, W. Sattler, Fr.-W. Bach, T. Duda, and W. Unterberg, "Nd-Fe-B permanent magnets (thick films) produced by a vacuum-spraying process," J. Appl. Phys., vol. 87, pp. 5329-5331, May 2000.

[12] B. Pawlowski, S. Schwarzer, A. Rahmig, and J. Topfer, "NdFeB thick films prepared by tape casting," J. Magn. Magn. Mater., vol. 265, pp. 337-344, 2003.

[13] S. Y. Xu, X. J. Huang, C. K. Ong, S. L. Lim, Y. L. Chang, Z. Yang, Z. W. Li, and H. B. Nie, "Yttria-stabilized zirconia: A suitable subsyrate for $c$-axis preferred $\mathrm{Nd}-\mathrm{Fe}-\mathrm{B}$ thin films fabricated by pulsed-laser deposition," J. Magn. Magn. Mater., vol. 222, pp. 182-188, 2000.

[14] U. Hannemanm, S. Fahler, V. Neu, B. Holzapfel, and L. Schultz, "Magnetic and microstructural properties of hard magnetic Nd-Fe-B films prepared on a Ta buffer by pulsed-laser deposition," IEEE Trans. Magn., vol. 38, no. 5, pt. 1, pp. 2805-2807, Sep. 2002.

[15] F. J. Cadieu, R. Rani, X. R. Qian, and L. Chen, "High coercivity SmCo based films made by pulsed laser deposition," J. Appl. Phys., vol. 83, pp. 6247-6249, Jun. 1998.

[16] J. M. Song, H. Sadakata, M. Nakano, Y. Kanai, H. Fukunaga, and J. G. Koh, "Effects of film thickness and droplets on magnetic properties of SmFeN films prepared by laser ablation technique," IEEE Trans. Magn., vol. 35, no. 5, pt. 1, pp. 3052-3054, Sep. 1999.
[17] M. Nakano, R. Katoh, H. Fukunaga, and F. Yamashita, "Fabrication of Nd-Fe-B thick-film magnets by high-speed PLD method," IEEE Trans. Magn., vol. 39, no. 5, pt. 2, pp. 2863-2865, Sep. 2003.

[18] M. Nakano, S. Sato, H. Fukunaga, and F. Yamashita, "Anisotropic Nd-Fe-B thick film magnets," J. Magn. Magn. Mater., vol. 303, no. 2, pp. e375-e378, Aug. 2006.

[19] M. Nakano, R. Kato, S. Hoefinger, J. Fidler, F. Yamashita, and H. Fukunaga, "Microstructure and magnetic properties of PLD-made Nd-Fe-B thick films," J. Alloys and Compounds, vol. 408-412, pp. 1422-1425, Feb. 2006.

[20] A. Yamazaki, M. Sendoh, K. Ishiyama, K. I. Arai, R. Kato, M. Nakano, and H. Fukunaga, "Wireless micro swimming machine with magnetic thin film," J. Magn. Magn. Mater., vol. 272-276, pp. e1741-1742, May 2004, Supplement 1.

[21] H. Fukunaga, K. Tokunaga, and J. M. Song, "Improvement in coercivity by high-speed crystallization for PrFeB-based nanocomposite magnets," IEEE Trans. Magn., vol. 38, no. 5, pp. 2970-2972, Sep. 2002.

[22] M. Yu, Y. Liu, S. H. Liou, and D. J. Sellmyer, "Nanostructured NdFeB films processed by rapid thermal annealing," J. Appl. Phys., vol. 83, no. 2, pp. 6611-6613, Jun. 1998.

Manuscript received October 31, 2006 (e-mail: mnakano@ nagasaki-u.ac.jp). 